Xiao-Jun Li*, Xu-Li Zeng, Li-Rui Che and Zhen Xu

\title{
Crystal structure of poly $\left[\left(\mu_{4}-(4 \mathrm{H}-1,2,4-\right.\right.$ triazol-4-yl) phenyl)acetato- $\left.\mathrm{K}^{4} N, N^{\prime}, O, O^{\prime}\right)$ (formiato- $\mathrm{\kappa}^{1} O$ ) cobalt(II)], $\mathrm{C}_{11} \mathrm{H}_{9} \mathrm{CoN}_{3} \mathrm{O}_{4}$
}

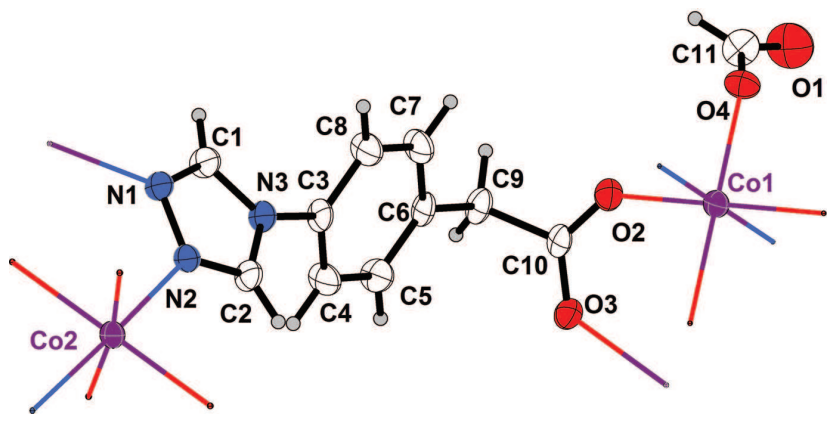

https://doi.org/10.1515/ncrs-2018-0541

Received November 29, 2018; accepted January 14, 2019; available online February 4, 2019

\section{Abstract}

$\mathrm{C}_{11} \mathrm{H}_{9} \mathrm{CoN}_{3} \mathrm{O}_{4}$, monoclinic, $C 2 / c$ (no. 15), $a=12.6503$ (9) $\AA$, $b=8.0959(6) \AA, \quad c=22.9723(14) \AA, \quad \beta=99.424(6)^{\circ}$, $V=2321.0(3) \AA^{3}, Z=8, R_{\mathrm{gt}}(F)=0.0370, w R_{\mathrm{ref}}\left(F^{2}\right)=0.1101$, $T=293(2) \mathrm{K}$.

\section{CCDC no.: 1890775}

The crystal structure is shown in the figure. Tables 1 and 2 contain details on crystal structure and measurement conditions and a list of the atoms including atomic coordinates and displacement parameters.

\section{Source of material}

A mixture of 4-(1,2,4-triazol-4-yl)phenylacetic acid (Htpa, $0.020 \mathrm{~g}, 0.1 \mathrm{mmol}), \mathrm{Co}\left(\mathrm{NO}_{3}\right)_{2} \cdot 6 \mathrm{H}_{2} \mathrm{O}(0.060 \mathrm{~g}, 0.2 \mathrm{mmol})$, DMF ( $4 \mathrm{~mL})$, EtOH $(1 \mathrm{~mL})$ and $\mathrm{H}_{2} \mathrm{O}(1 \mathrm{~mL})$ was added to a $23 \mathrm{~mL}$ Teflon bomb, and then heated to $120^{\circ} \mathrm{C}$ for $48 \mathrm{~h}$. After cooling to room temperature, pink crystals of the titled complex with block shape were obtained by filtration and washed with water and ethanol for several times.

\footnotetext{
*Corresponding author: Xiao-Jun Li, Department of Orthopedics, People's Hospital of Changshan, Quzhou, Zhejiang, China, e-mail: csrmyylxj@163.com

Xu-Li Zeng, Li-Rui Che and Zhen Xu: Department of Orthopedics, People's Hospital of Changshan, Quzhou, Zhejiang, China
}

๑ Open Access. ( 2019 Xiao-Jun Li et al., published by De Gruyter. (c) BY License.
Table 1: Data collection and handling.

\begin{tabular}{|c|c|}
\hline Crystal: & Pink block \\
\hline Size: & $0.22 \times 0.18 \times 0.07 \mathrm{~mm}$ \\
\hline Wavelength: & $\mathrm{Cu} K \alpha$ radiation $(1.54184 \AA)$ \\
\hline$\mu:$ & $11.8 \mathrm{~mm}^{-1}$ \\
\hline Diffractometer, scan mode: & SuperNova, $\omega$ \\
\hline$\theta_{\max }$, completeness: & $73.6^{\circ},>99 \%$ \\
\hline$N(h k l)_{\text {measured }}, N(h k l)_{\text {unique }}, R_{\text {int }}:$ & $4247,2265,0.030$ \\
\hline Criterion for $I_{\mathrm{obs}}, N\left(h k l_{\mathrm{gt}}\right.$ : & $I_{\text {obs }}>2 \sigma\left(I_{\text {obs }}\right), 2098$ \\
\hline$N(\text { param })_{\text {refined }}:$ & 174 \\
\hline Programs: & $\begin{array}{l}\text { Olex2 [1], SHELX [2], } \\
\text { CrysAlis }^{\text {PRO }} \text { [3] }\end{array}$ \\
\hline
\end{tabular}

\section{Experimental details}

$\mathrm{H}$ atoms bonded to $\mathrm{C}$ atoms from organic ligands were positioned geometrically and refined using a riding model, with $\mathrm{C}-\mathrm{H}=0.93 \AA$, with $U_{\text {iso }}(\mathrm{H})=1.2$ times $U_{\text {eq }}(\mathrm{C})$.

\section{Comment}

The rational design and fabrication of coordination polymers (CPs) that composed metal ion/cluster as nodes and organic ligands as connectors have flourished as an emerging area of research because of their beautiful structures as well as their potential applications in many important domains [4-6]. In general, the final properties of CPs are highly dependent on their structures, which are high related to their synthetic conditions and the selected building blocks [7]. Compared with the metal ion/cluster, the effect of organic ligands is more predictable. Organic ligands with $\mathrm{N}$ - and/or $\mathrm{O}$-donors have been extensively used to build novel MOFs with interesting structures and properties [8]. Recent literatures have revealed that the bifunctional organic ligands combining the carboxylate and triazole groups in one unit are good candidates for building CPs with interesting structures and promising bioactivities, which could be applied for the growth inhibition of human osteogenic sarcoma cells [9].

Single-crystal X-ray diffraction analysis revealed that the title complex crystallizes in the monoclinic system with space group $C 2 / c$ and demonstrates a three-dimensional framework structure. The asymmetric unit of the title structure contains two crystallographically independent $\mathrm{Co}$ (II) ions, one 
Table 2: Fractional atomic coordinates and isotropic or equivalent isotropic displacement parameters $\left(\AA^{2}\right)$.

\begin{tabular}{lrrrr}
\hline Atom & $\boldsymbol{x}$ & $\boldsymbol{y}$ & $\boldsymbol{z}$ & $\boldsymbol{U}_{\text {iso }}{ }^{*} \boldsymbol{U}_{\text {eq }}$ \\
\hline C01 & 0.500000 & 0.500000 & 0.500000 & $0.02391(17)$ \\
C02 & 0.250000 & $0.32206(7)$ & 0.500000 & $0.02309(17)$ \\
O1 & $0.7222(2)$ & $0.3586(4)$ & $0.62216(12)$ & $0.0623(7)$ \\
O2 & $0.49955(15)$ & $0.2629(3)$ & $0.46799(8)$ & $0.0330(4)$ \\
O3 & $0.33401(15)$ & $0.1558(2)$ & $0.45756(8)$ & $0.0328(4)$ \\
O4 & $0.66409(15)$ & $0.4822(2)$ & $0.53536(8)$ & $0.0326(4)$ \\
N1 & $0.45607(17)$ & $0.0836(3)$ & $0.08058(9)$ & $0.0289(5)$ \\
N2 & $0.36193(17)$ & $0.1696(3)$ & $0.07882(9)$ & $0.0266(4)$ \\
N3 & $0.42762(17)$ & $0.1178(3)$ & $0.17072(9)$ & $0.0300(5)$ \\
C1 & $0.4935(2)$ & $0.0535(4)$ & $0.13590(11)$ & $0.0326(6)$ \\
H1 & 0.556434 & -0.003975 & 0.149392 & $0.039^{*}$ \\
C2 & $0.3460(2)$ & $0.1881(3)$ & $0.13318(11)$ & $0.0298(5)$ \\
H2 & 0.287546 & 0.241469 & 0.144490 & $0.036^{*}$ \\
C3 & $0.4360(2)$ & $0.0987(4)$ & $0.23366(10)$ & $0.0299(5)$ \\
C4 & $0.3511(2)$ & $0.0330(4)$ & $0.25645(12)$ & $0.0374(6)$ \\
H4 & 0.287262 & 0.007874 & 0.231797 & $0.045^{*}$ \\
C5 & $0.3622(2)$ & $0.0048(4)$ & $0.31686(12)$ & $0.0368(6)$ \\
H5 & 0.304940 & -0.038729 & 0.332604 & $0.044^{*}$ \\
C6 & $0.4575(2)$ & $0.0408(3)$ & $0.35402(10)$ & $0.0287(5)$ \\
C7 & $0.5414(2)$ & $0.1095(4)$ & $0.32991(11)$ & $0.0365(6)$ \\
H7 & 0.605015 & 0.136701 & 0.354426 & $0.044^{*}$ \\
C8 & $0.5312(2)$ & $0.1380(4)$ & $0.26964(12)$ & $0.0374(6)$ \\
H8 & 0.587814 & 0.182956 & 0.253696 & $0.045^{*}$ \\
C9 & $0.4690(2)$ & $0.0069(3)$ & $0.41928(11)$ & $0.0319(6)$ \\
H9A & 0.543409 & -0.016302 & 0.434957 & $0.038^{*}$ \\
H9B & 0.426948 & -0.089607 & 0.425771 & $0.038^{*}$ \\
C10 & $0.4312(2)$ & $0.1546(3)$ & $0.45157(10)$ & $0.0263(5)$ \\
C11 & $0.7134(3)$ & $0.3713(4)$ & $0.56971(13)$ & $0.0407(7)$ \\
H11 & 0.747095 & 0.289325 & 0.551068 & $0.049^{*}$ \\
\hline & & & &
\end{tabular}

tpa-ligand and one $\mathrm{HCOO}^{-}$group derived from the decomposition of DMF. Both Co(II) atoms (Co1 and Co2, occupancy 0.5) locating on the special sites of the space group are sixcoordinated with two $\mathrm{N}$ atoms from two tpa-ligands and three carboxyl $\mathrm{O}$ atoms from three tpa-ligands as well as one $\mathrm{O}$ atom of the $\mathrm{HCOO}^{-}$group, shaping a distorted octahedral geometry. The $\mathrm{Co}(\mathrm{II})-\mathrm{O}$ bond distances are in the range of 2.055(2) to
2.107(2) $\AA$ and the Co(II)-N bond length is 2.129(2) $\AA$. As for the tpa ${ }^{-}$ligand, it binds with four $\mathrm{Co}(\mathrm{II})$ ions using its two carboxyl $\mathrm{O}$ atoms and two triazolyl $\mathrm{N}$ atoms to behave as a fourconnected node. The adjacent $\mathrm{Co}(\mathrm{II})$ ions are connected with each other via the carboxyl oxygen atoms and triazolyl groups along the $a$ axis to afford the 1D chain-like secondary building unit chains, which are further joint via the tpa-ligands to shape a three-dimensional framework structure.

\section{References}

1. Dolomanov, O. V.; Bourhis, L. J.; Gildea, R. J.; Howard, J. A. K.; Puschmann, H.: OLEX2: a complete structure solution, refinement and analysis program. J. Appl. Crystallogr. 42 (2009) 339-341.

2. Sheldrick, G. M.: Crystal structure refinement with SHELXL. Acta Crystallogr. C71 (2015) 3-8.

3. Agilent Technologies: CrysAlis ${ }^{\mathrm{PRO}}$ Software system, version 1.171.35.15. Agilent Technologies UK Ltd, Oxford, UK (2011).

4. Mukherjee, S.; Ganguly, S.; Manna, K.; Mondal, S.; Mahapatra, S.; Das, D.: Green approach to synthesize crystalline nanoscale Zn(II)-coordination polymers: cell growth inhibition and immunofluorescence study. Inorg. Chem. 57 (2018) 4050-4060.

5. Li, Y.; Lan, D.: Crystal structure of catena-poly $\left[\left(\mu_{2}-3,3^{\prime}-\right.\right.$ thiodipropionato- $\mathrm{K}_{2} \mathrm{O}: \mathrm{O}^{\prime}$ )-(bipyridine- $\left.\mathrm{K}^{2} \mathrm{~N}, \mathrm{~N}\right)$ copper(II)], $\mathrm{C}_{16} \mathrm{H}_{16} \mathrm{CuN}_{2} \mathrm{O}_{4}$ S. Z. Kristallogr. NCS 233 (2018) 987-988.

6. Zhai, Q. G.; Bu, X.; Zhao, X.; Mao, C.; Bu, F.; Chen, X.; Feng, P.: Advancing magnesium-organic porous materials through new magnesium cluster chemistry. Cryst. Growth Des. 16 (2016) 1261-1267.

7. Hauptvogel, I. M.; Bon, V.; Grünker, R.; Baburin, I. A.; Senkovska, I.; Mueller, U.; Kaskel, S.: A family of 2D and 3D coordination polymers involving a trigonal tritopic linker. Dalton Trans. 41 (2012) 4172-4179.

8. Qiu, Y.; Liu, H.; Ling, Y.; Deng, H.; Zeng, R.; Zhou, G.; Zeller, M.: 3D $\mathrm{Ln}-\mathrm{Ag}(\mathrm{Ln}=\mathrm{Nd}$; Eu) Coordination polymers based on $\mathrm{N}$ - and $\mathrm{O}$-donor ligands: synthesis, crystal structures and luminescence. Inorg. Chem. Commun. 10 (2007) 1399-1403.

9. Dietzel, P. D. C.; Blom, R.; Fjellvåg, H.: Base-induced formation of two magnesium metal-organic framework compounds with a bifunctional tetratopic ligand. Eur. J. Inorg. Chem. 2008 (2008) 3624-3632. 